\title{
Imigração, Estado de direito e biopolítica
}

\author{
Immigration, Rule of law and biopolitics
}

\section{Márcio Alves da Fonseca*}

Pontifícia Universidade Católica de São Paulo (PUC-SP), São Paulo, SP, Brasil

\section{Resumo}

O artigo procura discutir a atualidade da noção de biopolítica, cuja formulação inicial é dada por Foucault no ano de 1976, simultaneamente no livro A vontade de saber e no curso Em defesa da sociedade. Para tanto, toma o problema da "crise de imigração" dos últimos anos, compreendida como uma expressão da biopolítica em uma de suas concretizações extremas, na medida em que revela o acoplamento entre o domínio jurídicoestatal, os mecanismos disciplinares dos corpos e os mecanismos de segurança das populações. A partir deste exemplo, pretende refletir sobre os limites do Estado de direito que, sendo uma das categorias jurídico-políticas que se constitui como paradigma da política ocidental moderna, encontra-se confrontado com os efeitos da biopolítica no presente.

Palavras-chave: Foucault. Biopolítica. Imigração. Estado de direito.

* MAF: Doutor em Direito, e-mail: mafonseca@pucsp.br 


\section{Abstract}

The article discusses the relevance for the presente time of the notion of biopolitics, which the original formulation is carried out by Foucault in 1976, in the book La volonté de savoir and in the course II faut défendre la société. Therefore, take the problem of "immigration crisis" in recent years, understood as an expression of biopolitics in one of its extreme achievements, in that it reveals the coupling between the legal-state area, the disciplinary mechanisms of the body and security mechanisms of the populations. From this example, the article argue about the limits of the rule of law, one of the legal-political categories which constituted a paradigm of modern Western politics and that is faced in our time with the effects of the biopolitics.

Keywords: Foucault. Biopolitics. Immigration. Rule of law.

\section{Introdução}

A atual profusão dos estudos em torno da noção de biopolítica, considerada a partir da formulação que lhe é conferida por Michel Foucault, faz-nos perder de vista a relativa juventude desta noção. No âmbito dos escritos de Foucault, em sua caracterização inicial mais precisa, sua formulação remete ao ano de 1976, inserindo-se simultaneamente em dois trabalhos daquele ano. De um lado, o primeiro volume da História da sexualidade, A vontade de saber (FOUCAULT, 1997) e, de outro, o curso proferido no Collège de France, Em defesa da sociedade (FOUCAULT, 1999). Ainda que o termo "biopolítica" tenha sido utilizado pelo filósofo anteriormente a estes dois trabalhos ${ }^{1}$, é neles que a noção será de fato elaborada.

1 Foucault utiliza pela primeira vez o termo "biopolítica" em 1974, em uma das conferências sobre a medicina social, proferidas no Brasil: FOUCAULT, M. La naissance de la médecine sociale. In: FOUCAULT, M. Dits et écrits, v. III. Paris: Gallimard, 1994, p. 207-228. 0 tema da biopolítica aparecerá também em outra conferência proferida no Brasil, agora já em 1976: FOUCAULT, M. Les mailles du pouvoir. In: FOUCAULT, M. Dits et écrits, v. IV. Paris: Gallimard, 1994, p. 182-201. No mesmo ano, a noção retorna na resenha feita por Foucault do livro de Jacques Ruffié, De la biologie à la culture, publicada primeiramente no Le Monde e posteriormente em Ditos e escritos: FOUCAULT, M. Biohistoire et biopolitique. In: FOUCAULT, M. Dits et écrits, v. III. Paris: Gallimard, 1994, p. 95-97. 
No âmbito da analítica do poder construída por Foucault, a explicitação dos limites das principais versões do modelo essencialista ou substancial do poder - denominado em termos gerais de modelo jurídico-discursivo - receberá uma forma importante nestes trabalhos de 1976. Em linhas gerais, pode-se dizer que em oposição à versão do modelo jurídico-discursivo o qual identifica o poder às ideias de repressão e de interdição, A Vontade de saber mostrará o poder em seu caráter de incitação e de produção de discursos e práticas. Por sua vez, em oposição à versão do modelo jurídico-discursivo que identifica o poder à ideia de ordem instaurada pela lei, ambas vinculadas à estrutura estatal, Em defesa da sociedade irá considerar o poder em termos de uma guerra perpétua ${ }^{2}$. Por meio dessas duas vias diferentes, Foucault expõe os limites das concepções de poder dominantes no pensamento político ocidental, na medida em que explicita a forma predominante do funcionamento do poder na atualidade: a forma de uma biopolítica das populações.

Desse modo, ao lado dos mecanismos da disciplina, por meio dos quais teria se constituído no Ocidente, a partir do final do século XVII, uma anatomopolítica dos corpos, uma biopolítica das populações caracterizaria o funcionamento do poder no presente. Os mecanismos de segurança da biopolítica incidem sobre a vida biológica dos indivíduos e dos grupos, permitindo a regulação de seus processos naturais, avaliando estes processos segundo o critério dos riscos, estabelecendo relativamente a eles curvas normais e curvas desfavoráveis e, assim fazendo, constituem-se no esteio da racionalidade política segundo a qual os homens são governados.

Segundo as análises realizadas por Foucault no curso Segurança, território, população (FOUCAULT, 2008a), os mecanismos de segurança da biopolítica não tomam o lugar dos mecanismos disciplinares que, por sua vez, não teriam substituído os mecanismos jurídico-legais (cf. FOUCAULT, 2008a, p. 11). Concretamente, nas sociedades ociden-

2 Este paralelismo entre $A$ Vontade de saber e Em defesa da sociedade, relativamente à explicitação dos limites às duas principais versões do modelo jurídico-discursivo do poder é sugerida por GROS, F. Michel Foucault. 2. ed. Paris: PUF, 1998, p. 77-80. 
tais ocorreu a colonização recíproca entre estes três modos de funcionamento do poder, sua sobreposição e penetração. De tal modo que uma inflação do código jurídico-legal é continuamente suscitada para fazer funcionar os sistemas de segurança, ao mesmo tempo em que os mecanismos de disciplina dos corpos são ativados e reinvestidos pelos mecanismos da biopolítica (cf. FOUCAULT, 2008a, p. 11).

Ora, no contexto das artes de governar liberal e neoliberais, as implicações entre uma "gestão macroscópica das populações", um "controle micropolítico dos corpos" (cf. MACMILLIAN, 2010) e uma atuação jurídico-administrativa exercida pelos Estados revela, de modo concreto e historicamente encarnado, o funcionamento da política na atualidade. Trata-se de uma biopolítica concretizada em sua forma extrema: aquela que revela um acoplamento perfeitamente ajustado entre o jurídico-estatal, o disciplinar e o seguracional.

Nesse sentido, para destacar a atualidade da noção de biopolítica formulada por Foucault, considerada como rede de inteligibilidade para a análise de fenômenos que nos são contemporâneos, tomaremos o problema da imigração, no qual se pode perceber o acoplamento mencionado, poucas vezes configurado com tanta nitidez.

\section{"Crise de imigração" e biopolítica}

Tendo por centro de convergência principal os países da Europa e por cenário privilegiado o mediterrâneo, a chamada "crise de imigração" atual explicita a magnitude e, sobretudo, os impasses dos deslocamentos populacionais neste início do século XXI. Perante esta magnitude e estes impasses, torna-se difícil vislumbrar qualquer forma de acomodação razoável para a imensa massa de pessoas que se encontram aprisionadas em um movimento para o qual não se vislumbra porto de chegada.

A imagem mais comum associada a este movimento migratório é a do barco e das figuras que o circundam: os locais de partida, a busca por um porto, as navegações à deriva, os naufrágios, as tentativas de resgate, os afogamentos. 
Muitas dessas figuras assombram, como a do corpo do menino sírio-curdo, Aylan Kurdi, encontrado na praia da ilha grega de Kos, imagem que se tornou símbolo da crise migratória na Europa. Muitas dessas figuras surpreendem por revelarem de maneira tão direta o significado profundo do desespero, como aquelas dos barcos afundados pelos próprios passageiros, como último recurso para serem resgatados.

As centenas de barcos, que transportam milhares de nossos contemporâneos, sugerem uma triste analogia com outras embarcações trágicas, pertencentes a outra época. É quase imediata a remissão às "naus dos loucos", que habitavam simbólica e materialmente a paisagem da Renascença, descritas por Foucault em História da loucura (FOUCAULT, 1987): naus repletas de passageiros que não pertenciam a lugar nenhum; embarcações destinadas a atracar em muitos portos, mas jamais desembarcar em definitivo seus ocupantes; naus portadoras de inquietudes e de medos suscitados pelo estranhamento perante o outro e o diferente; barcos que se constituíam signo de uma existência errante, cuja pretensão em fixar-se era considerada ônus e ameaça.

As épocas são diferentes, os passageiros são outros, as marcas, porém, são muito semelhantes: ausência de lugar no mundo, errância sem destino certo ou seguro, estigma da diferença, rejeição por parte daqueles que detém um lugar.

Os números acerca desses novos "prisioneiros da passagem"3 também impressionam. Até meados de 2015, a União europeia havia registrado mais de 108.000 chegadas de imigrantes (GEMENNE, 2015) e, diferentemente do que afirmam alguns especialistas, estes fluxos migratórios não se devem a fatores eminentemente econômicos, mas constituem principalmente deslocamentos de refugiados. De fato, até o final de julho de 2015, 62\% daqueles que tentaram chegar à Europa em embarcações vinham da Síria, da Eritréia e do Afeganistão, países assolados seja pela guerra, pela opressão ditatorial ou por extremismos

3 A expressão "prisioneiro da passagem" é utilizada por Foucault em História da loucura para designar os passageiros das "naus dos loucos" na Renascença, destinados a vagar indefinidamente, sem jamais encontrar um porto de chegada. Nas palavras de Foucault, o louco "é um prisioneiro no meio da mais livre, da mais aberta das estradas: solidamente acorrentado à infinita encruzilhada. É o passageiro por excelência, isto é, o prisioneiro da passagem" (FOUCAULT, 1987, p. 12). 
religiosos. Se aos imigrantes destes países acrescentar-se os oriundos de Darfur, do Iraque, da Somália e da Nigéria, a proporção de imigrantes que se enquadram na categoria de refugiados chega a $70 \%$ (KINGSLEY, 2015).

Isso faz com que o deslocamento populacional ao qual assistimos combine quase todos os elementos dos grandes modelos migratórios até hoje catalogados: constitui-se como fluxo contínuo, dá-se numa escala maciça, é resultante de guerras civis, ditaduras e extremismos religiosos, dos quais se originam todo tipo de carências, como condições materiais de existência, liberdade, segurança e paz (cf. MORICE, 2015).

As iniciativas de acolhimento dos refugiados tomadas por alguns países europeus estão longe de acenarem para uma resposta à altura da dimensão do problema. Repete-se a lógica do "asilo mais próximo", já aplicada pela agência da ONU encarregada de fixar os refugiados palestinos no pós-guerra e nos anos 1990, quando da guerra civil na ex-Iugoslávia. Esta mesma lógica foi retomada em 2004 pelo Alto Comissariado das Nações Unidas para os refugiados. Denominada de burden sharing (partilha do fardo), trata-se de compelir aos países geograficamente mais próximos que "assumam a sua parte" na partilha do ônus constituído pelos imigrantes. Por isso, estima-se que hoje $80 \%$ do "fardo" recaia sobre os países pobres e vizinhos das zonas de irradiação dos principais deslocamentos migratórios (cf. MORICE, 2015, p. 211).

Desse modo, o destino de grande parte desta imensa população de imigrantes, parece ser, pelo menos por muito tempo ainda, os "campos". Eis que os barcos finalmente chegam a algum lugar. Mas esse lugar é tão provisório quanto a travessia que conduziu até ele e, ao mesmo tempo, tão definitivo quanto a insuperável condição de passagem em que se encontram seus milhares de passageiros. $\mathrm{O}$ campo não constitui um porto para o desembarque, ele segue sendo um não-lugar.

Em suas diversas faces, esta realidade do deslocamento migratório no presente coloca-nos diante da biopolítica em uma de suas concretizações extremas. De um lado, a realidade dessas imigrações comporta a especificação de uma população como corpo vivo em movimento, corpo coletivo cujas cabeças se pode contar, cujas origens se 
pode identificar, cujas marcas vitais se pode medir e calcular. De outro lado, nessa realidade se cruzam e se interpenetram tanto o poder em sua forma juridicamente estabelecida dos Estados quanto a vida biológica inteiramente exposta, inteiramente aberta ao atravessamento por toda sorte de gerenciamentos políticos. Por fim, é uma realidade que se constitui sob o signo do campo como seu destino natural. $\mathrm{O}$ campo emerge como o não-lugar que se configura, ao mesmo tempo, como lugar privilegiado para uma anatomopolítica dos corpos e uma biopolítica das populações. Nele se dá uma atuação político-administrativa cuja função é controlar a distância, gerir a separação e regular toda forma de assimilação dos corpos e da vida.

\section{Biopolítica e Estado de direito}

Diante deste cenário, somos confrontados senão com o esvaziamento, ao menos com os limites de algumas categorias jurídico-políticas que se constituíram como paradigmas da política ocidental moderna de feição democrática e garantidora das liberdades e da dignidade da pessoa humana, e que, ainda hoje, constituem o seu principal fundamento.

Dentre essas categorias, uma se destaca: o chamado Estado de direito, cujo princípio básico, nas palavras de Canotilho (1999, p. 7) é a "eliminação do arbítrio no exercício dos poderes públicos com a consequente garantia de direitos dos indivíduos perante esses poderes".

Devendo ser compreendido como uma criação da "cultura política ocidental" (CANOTILHO, 1999, p. 7) o Estado de direito construiu uma "arquitetônica de Estado baseada no consenso sobre princípios e valores que, em seu conjunto, formam a chamada juridicidade estatal" (CANOTILHO, 1999, p. 7). Em Direito Constitucional e Teoria da Constituição, Canotilho (1998, p. 235-272) faz uma síntese das dimensões fundamentais desta juridicidade estatal que, em seu conjunto, acabou por produzir, historicamente, o Estado de direito como "paradigma de organização política considerado como referência relativamente a outros esquemas organizatórios do político": a ideia do governo de leis 
(e não de homens) gerais e racionais; a organização do poder segundo o princípio da divisão dos poderes; o primado do legislador; a garantia de tribunais independentes; o reconhecimento de direitos, liberdades e garantias; o pluralismo político; o funcionamento do sistema organizatório estatal subordinado aos princípios da responsabilidade e do controle; o exercício do poder estatal por meio de instrumentos jurídicos constitucionalmente determinados.

Ora, estas dimensões da juridicidade, em seu conjunto, forjaram o paradigma histórico da organização política a que chamamos Estado de direito, e são elas que portam os princípios e os valores materiais os quais constituem o Estado de direito em sua formulação moderna: a liberdade do indivíduo, a segurança individual e coletiva, a responsabilidade e a responsabilização dos titulares do poder, a igualdade de todos os cidadãos, a proibição de discriminação de indivíduos e grupos.

Na medida em que estes valores e princípios são efetivados por meio de instituições, de procedimentos de ação e de formas de organização de poderes e de competências que expressem um poder democrático ou uma soberania popular ou uma representação política democraticamente instituída, configura-se o Estado de direito em sua feição de Estado constitucional de direto democrático e social, acrescentando-se aí, mais recentemente, a qualidade de Estado ambientalmente sustentado.

Ainda que seja necessário fazer a distinção entre o Estado de direito meramente formal e o Estado de direito que materialmente se configura como um Estado justo, não se pode negar que essa forma de organização jurídico-política se constitui num dos principais paradigmas da cultura política ocidental moderna.

Pois bem, no contexto de uma biopolítica que assume formas de concretização extremas como, por exemplo, na situação dramática da imigração em nossos dias, este paradigma se defronta com a ameaça de seu esvaziamento ou, ao menos, com limites que acenam para esta ameaça.

Mais precisamente em torno do problema da imigração, avancemos na hipótese de que nos encontramos diante da ameaça de 
esvaziamento do Estado de direito no contexto da biopolítica, recorrendo a algumas análises de Didier Fassin e de Danièle Lochak.

No artigo $O$ corpo exposto. Ensaio de economia moral da ilegitimidade (FASSIN, 2004), ao discutir os usos políticos do corpo perante a gestão do Estado francês relativamente a duas populações - de um lado, a população dos "desempregados e precarizados", que solicitam um seguro de urgência, e de outro lado, a população dos "imigrantes ilegais", que solicitam um visto de permanência - Fassin explicita alguns dos impasses nas relações entre o corpo do imigrante, a administração das populações imigradas e o Estado de direito.

Para sua análise, o sociólogo parte das modificações ocorridas na legislação francesa sobre a imigração com a chamada loi Reseda, de 1997, pelas quais se prevê o direito ao visto de permanência e o direito ao trabalho regular a estrangeiros imigrantes doentes.

Segundo o autor, o procedimento que permite o reconhecimento deste direito apoia-se em um protocolo que se tornou mais e mais preciso na medida em que foi mais e mais explicitamente incluído na própria legislação ${ }^{4}$. Em princípio, cabe a um médico inspetor da direção departamental dos "Assuntos Sanitários e Sociais", instruído pelos serviços da prefeitura, dar o seu parecer, apoiado no dossiê relativo ao demandante do visto, enviado pelo médico que o atendeu em algum serviço público de saúde. A lei prevê que o parecer do médico inspetor seja balizado por dois critérios os quais permitirão a verificação do fundamento da demanda: a) que o estado de saúde do demandante seja julgado suficientemente grave; b) que o acesso ao tratamento no país de origem do imigrante seja considerado improvável. Os dois critérios são submetidos à apreciação pessoal do médico inspetor. Uma vez transmitido à prefeitura, o parecer do médico inspetor, quando recomenda a aprovação do pedido de permanência e sugere a duração do visto, quase sempre é acatado pelo serviço de estrangeiros, salvo se houver a invocação de algum tipo de ameaça à ordem pública, decorrente de uma medida judiciária seguida de um delito cometido pelo imigrante.

4 Para a exposição que se segue ver FASSIN, 2004, p. $246 s s$. 
De acordo com os estudos de Fassin, nesse procedimento, além do caráter contingente da apreciação pessoal realizada pelo médico, para a qual não há nenhum critério absoluto, dois outros fatores são constantes.

Em primeiro lugar, a narrativa que instrui o processo é fragmentária. Não se espera que ela seja exaustiva nem linear, mas ela visa trazer "fragmentos de vida pertinentes" (FASSIN, 2004, p. 247). O imigrante deve relatar os acontecimentos patológicos, com o duplo ônus de arguir sobre a gravidade da sua doença e sobre a inacessibilidade aos tratamentos em seu país. Em segundo lugar, o elemento declarativo não basta. A administração pública não se contenta com a palavra do declarante, sendo a ele necessário comprovar documentalmente sua veracidade, por meio do dossiê médico.

Essa dupla justificação - pela história do imigrante e pelos documentos oficiais - permite então questionar o significado da narrativa exigida ao demandante, uma vez que ela não valerá se não estiver acompanhada da comprovação documental.

No entanto, segundo o entendimento de Fassin, a narrativa serve para conferir à demanda "uma perspectiva mais global e ao mesmo tempo mais individual sobre aquele que a formula" (FASSIN, 2004, p. 248). Ela prova a boa-fé do requerente que aceita revelar-se, contrapartida necessária da troca de prestações entre o Estado e seus sujeitos (cf. FASSIN, 2004, p. 248). Por isso ela acaba sendo uma peça fundamental em todo o dispositivo: "a administração se humaniza a partir desta individualização dos tratamentos". E a narrativa seria "o suplemento de alma da gestão das requisições" apresentadas ao Estado (FASSIN, 2004, p. 248).

No âmbito destas narrativas é que são mobilizados os principais "tópicos do infortúnio": a necessidade, provada pelos corpos através das privações por que passa, como a fome e o frio, assim como dos sintomas da doença que carrega; a compaixão, que situa o corpo em uma relação com a simpatia e a proximidade (simpatia que em geral é buscada pela evocação às crianças, cuja vulnerabilidade e inocência tornam o infortúnio ainda mais intolerável); o mérito, mostrado pelo corpo que não fugiu ao seu dever de observar as exigências terapêuticas e que está 
disposto a submeter-se a quaisquer outras que lhe forem atribuídas; a justiça, que curiosamente é pouco trazida nas narrativas, uma vez que a exposição de si e de seus sofrimentos, com o intuito de obter um visto de permanência, se presta pouco a manifestar uma reivindicação de direitos (cf. FASSIN, 2004, p. 248-251).

Para além da diversidade desses tópicos, do infortúnio nos quais se apoiam as justificativas das demandas feitas ao Estado, o ponto comum presente nas narrativas é a tentativa de se construir o vínculo entre a situação social do demandante e as alterações do seu corpo e do corpo de seus próximos.

Trata-se de "utilizar seu corpo como um último recurso na troca negociada com o Estado" (FASSIN, 2004, p. 252). A obtenção do visto de permanência aparece então como o remédio contra a decadência do corpo que se vê, mas também do "corpo invisível da experiência do sofrimento social" (FASSIN, 2004, p. 252).

O desvelamento dos infortúnios dos corpos e sua narrativa são objeto de uma atenção particular do governo, que se vê compelido a dar uma resposta adequada à racionalidade política que o informa e, ao mesmo tempo, uma resposta efetiva, supostamente legítima e justa, à situação daquelas pessoas, dado que os infortúnios que as narrativas expõem se referem a uma questão considerada politicamente delicada: a imigração.

Reaproximamo-nos aqui da ideia de um esvaziamento do Estado de direito perante uma das concretizações mais contundentes da biopolítica no presente, a questão dos deslocamentos populacionais. Diante desta concretização biopolítica de nosso tempo, pode-se questionar a insuficiência das respostas que o Estado de direito tem sido capaz de oferecer. Ainda que, formalmente, a juridicidade estatal oriente estas respostas, percebe-se o quanto estão distantes de possuírem efetividade, de serem dotadas de legitimidade e, no limite, de serem justas.

Referindo-se à legislação francesa de imigração relativa aos imigrantes doentes, Fassin sugere que o poder dos agentes do Estado em tratar os dossiês constituídos por um procedimento, o qual se apoia em narrativas sobre o infortúnio, submeteria o Estado a um tipo de escolha a que denomina "escolha patética". Com essa expressão designa as 
ações do Estado que "visam alocar recursos escassos, que são ao mesmo tempo condicionantes da existência material e social das pessoas concernidas e cuja atribuição é decidida num contexto de espetacularização ou de discursividade do sofrimento" (FASSIN, 2004, p. 253).

Três critérios estariam aqui reunidos: a raridade dos recursos (os vistos de permanência, por exemplo, são bens raros num contexto em que as políticas de imigração se mostram cada vez mais restritivas); o condicionamento, mediante seu recebimento, da existência material e social das pessoas (os vistos de permanência, uma vez que autorizam uma existência legal, o acesso ao emprego e aos bens sociais, condicionam a participação na vida do Estado); e a espetacularização e discursividade do sofrimento (que são a substância das narrativas que poderão ensejar a proteção ou a prestação demandada ao Estado) (cf. FASSIN, 2004, p. 253-254).

Nas palavras de Fassin, este tipo de escolha patética dos Estados, muito mais comum do que pode parecer, resulta justamente de "uma associação entre escassez de recursos, implicação de vida e de morte e confronto direto com o sofrimento do outro" (2004, p. 254).

É possível identificarmos aqui os limites das ações dos Estados europeus diante da atual crise de imigração. As escolhas patéticas destes Estados enquadram-se no tipo de respostas que são capazes de oferecer, num contexto no qual a política se configura, como uma biopolítica. Esboça-se, nas ações destes Estados, uma forma de escolha e de atuação jurídico-administrativa que se constitui ao mesmo tempo como apropriação micropolítica dos corpos e como gestão macroscópica das populações, relativamente à qual o paradigma do Estado de direito se vê esvaziado em seus princípios e na dinâmica pretendida entre eles.

Acompanhando os estudos de Didier Fassin sobre a legislação francesa relativa à imigração, Danièle Lochak igualmente discute os sintomas do esvaziamento do paradigma do Estado de direito tal como o conhecemos (LOCHAK, 2001). A autora comenta de que forma as modificações introduzidas nesta legislação pela lei de 1997 - que dispõe sobre a condição de permanência do imigrante doente - traduzem uma inversão de perspectiva importante: a doença, anteriormente fonte de suspeita, torna-se fonte de reconhecimento social; "mais 
concretamente, lá onde ela era reconhecida como exclusão, é doravante reconhecida como um modo de acesso ao visto de permanência" (LOCHAK, 2001, p. 35).

Desse modo, uma "razão humanitária" se introduz na administração das populações de imigrantes. Porém, essa nova regulamentação, sua aplicação e os procedimentos adotados, acabam por desembocar numa taxa de aceitação dos pedidos de visto de permanência muito variável, de acordo com as diferentes regiões e departamentos, indicando uma vulnerabilidade maior ou menor dos imigrantes na obtenção de seus direitos, dependendo da região em que se encontram.

Lochak mostra os paradoxos da inscrição de considerações humanitárias no quadro da lei. Esta inscrição "desemboca em uma regra complexa, dotada de nuances, cuja aplicação está sujeita a divergências de apreciação, em contradição com os princípios de segurança jurídica e de igualdade perante a lei" (LOCHAK, 2001, p. 36). De certo modo, o "arbitrário" que o Estado de direito queria banir, ressurge. E, uma vez que o controle dos fluxos migratórios segue sendo a principal preocupação das autoridades que possuem poder de decisão , a regra jurídica (de aparência liberal), não produz os resultados pretendidos (a proteção efetiva dos imigrantes doentes), segundo os princípios da liberdade, da igualdade, da segurança jurídica, da justiça (cf. LOCHAK, 2001, p. 36).

Daí o jogo delicado, no Estado de direito, entre a "razão humanitária" e a "razão jurídica". Segundo Lochak, o registro humanitário é guiado por um sentimento de benevolência, pela compaixão relativamente aos infortúnios dos outros. Trata-se de uma perspectiva reparadora, compensatória. Muito diferente é a proteção fundada sobre o direito, que supõe o indivíduo possua direitos reconhecidos, cujo respeito ele pode exigir.

No Estado de direito, a razão humanitária será sempre mais frágil do que a razão jurídica. É muito diferente a situação em que um imigrante preenche as condições previstas legalmente e que lhe dão direito à obtenção de um título de permanência, podendo, em caso de recusa da administração pública, recorrer aos tribunais daquela situação em que a lei não lhe confere propriamente um direito, mas apenas prevê 
o reconhecimento, por parte da autoridade pública, a título humanitário, das condições que autorizam a concessão do título de permanência. Nesse caso, trata-se de um ato de pura benevolência, que apenas indica o sentimento de humanidade de seu autor (a administração pública), mas não indica um direito (cf. LOCHAK, 2001, p. 36-37).

No quadro do Estado de direito, instaurar-se-ia, portanto, o arbitrário, que decorre da perversão da "razão jurídica" pela "razão humanitária". Esta perversão se faz presente, como vimos, no caráter aleatório da concessão de vistos de permanência por motivos médicos. Todas as condições postas pela lei quanto a estas situações estão sujeitas a divergências de apreciação e de interpretação de um médico para outro, de uma região para outra, de uma autoridade administrativa para outra (cf. LOCHAK, 2001, p. 38). Ocorre aqui, como afirma Danièle Lochak, "uma entorse evidente nos próprios fundamentos do Estado de direito, que supõe a segurança jurídica e ao mesmo tempo a igualdade de tratamento no conjunto do território" (2001, p. 39).

\section{Considerações finais}

\section{Haveria um porto entre a bipolítica e o Estado de direito?}

O drama da atual "crise de imigração" está longe de ter uma solução. O fluxo das populações não dá sinais de diminuição, evidentemente porque as situações que os provoca continuam a operar fortemente. As fronteiras dos países, seja daqueles visados como lugar de passagem seja daqueles buscados como destino final, são fortalecidas. O arranjo político entre os Estados, supostamente mais concernidos, é lento, contraditório, normativo e, sobretudo, economicamente orientado. O não-lugar dos campos se multiplica.

Dentre tantas indefinições, uma pergunta se destaca: haveria um porto entre a biopolítica e o Estado de direito? A sua necessária formulação, que em parte foi inaugurada pelas análises de Michel Foucault acerca da biopolítica, encontra-se hoje reafirmada. Numa configuração em que, de um lado, o corpo surge como último recurso para a obtenção 
das prestações do Estado e a vida das populações que se torna o âmbito privilegiado da política e, de outro lado, os Estados formalmente constituídos a partir do paradigma da juridicidade e dos direitos operam segundo uma racionalidade política na qual o valor e o lugar efetivo da vida dos homens são economicamente determinados, nos cabe perguntar se o destino do Estado de direito seguirá sendo aquele de efetivar escolhas patéticas.

Num tempo em que novas naus trágicas navegam sem perspectiva de chegarem a um porto e em que novos "prisioneiros da passagem" seguem sem possibilidade de encontrar um lugar, as escolhas dos Estados modernos parecem defrontar-se, finalmente, com seus limites.

\section{Referências}

CANOTILHO, J. J. G. Estado de Direito. Cadernos Democráticos 7. Lisboa: Edição Fundação Mario Soares e Gradiva, 1999.

CANOTILHO, J. J. G. Direito Constitucional e Teoria da Constituição. 2. ed. Coimbra: Almedina, 1998.

FASSIN, D. Le corps exposé. Essai d'économie morale de l'illégitimité. In: FASSIN, D. et MEMMI, D. Le gouvernement des corps. Cas de Figure 3. Paris: Éditions de l'École des hautes études en sciences sociales, 2004. p. 237-266.

FOUCAULT, M. História da loucura na Idade Clássica. Trad. José Teixeira Coelho Netto. 2. ed. São Paulo: Perspectiva, 1987.

FOUCAULT, M. A vontade de saber. Trad. Maria Thereza da Costa Albuquerque e J. A. Guilhon Albuquerque. 12. ed. Rio de Janeiro: Graal, 1997.

FOUCAULT, M. Em defesa da sociedade. Trad. Maria Ermantina Galvão. São Paulo: Martins Fontes, 1999.

FOUCAULT, M. Segurança, território, população. Trad. Eduardo Brandão. São Paulo: Martins Fontes, 2008a. 
FOUCAULT, M. Nascimento da biopolítica. Trad. Eduardo Brandão. São Paulo: Martins Fontes, 2008b.

GEMENNE, F. Migrants, ce n'est pas tant une crise de l'immigration qu'une crise de l'Europe. Entrevista veiculada por RT en français, 21 août 2015.

GROS, F. Michel Foucault. 2. ed. Paris: PUF, 1998.

KINGSLEY, P. 10 truths about Europe's migrant crisis. The Guardian, 10 august 2015.

LOCHAK, D. L'humanitaire, perversion de l'État de droit. Sciences sociales et Santé, Paris, v. 19, n. 4, p. 35-42, dec. 2001.

MACMILLIAN, A. La biopolitique et le dressage des populations. Dossier Biopolitique et gouvernements des populations. Cultures $\mathcal{E}$ Conflits, Paris, n. 78, p. 39-53, 2010.

MORICE, A. Situation actuelle des migrations internationales: réalités et controverses. L'information psychiatrique, Paris, v. 91, n. 3, p. 207-215, mars 2015.

Recebido: 02/10/2016

Received: 10/02/2016

Aprovado: 03/11/2016 Approved: 11/03/2016 